JTTEE5 25:1375

DOI: 10.1007/s11666-016-0463-z

1059-9630/\$19.00 C ASM International

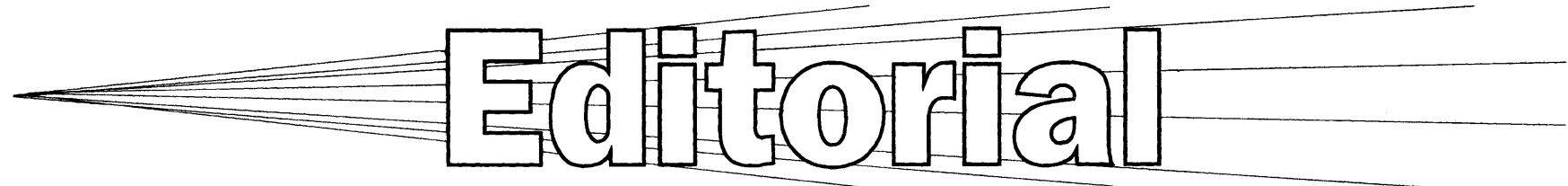

\title{
7th Asian Thermal Spray Conference (ATSC 2015), Xi'an, China, September 23-25, 2015
}

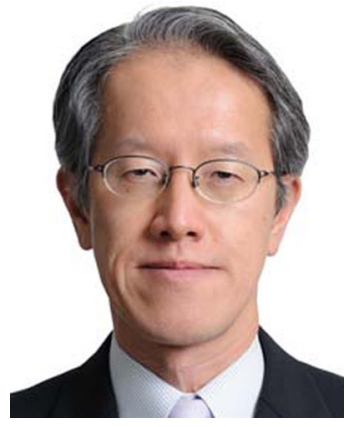

Seiji Kuroda

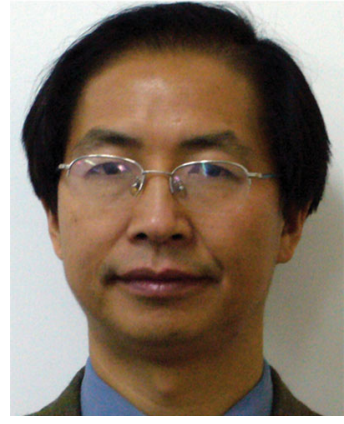

Chang-Jiu Li

This special issue of the Journal of Thermal Spray Technology (JTST) includes selected papers that were presented at the 7th Asian Thermal Spray Conference (ATSC 2015) held at Xi'an, China, on September 2325, 2015. Over the years, the ATSC Conference Series has emerged as a flagship event of the Asian Thermal Spray Society (ATSS) in the AsiaPacific region, with the previous ATSCs having been held in Japan (twice), Korea, Singapore, China, and India. The JTST special issue for the ATSC papers began with the 4th ATSC that was held at Xi'an, China, in 2009 to share the latest progress of thermal spray technology in Asia. This ATSC conference was held in China for a second time, with 157 participants representing the Asian countries involved in thermal spraying. In addition to experts from Asian countries, renowned experts from European countries were also invited to share their latest advances in thermal spray science and technology. In total, the 2-day conference resulted in exciting technical presentations, with a program that included five plenary talks, 63 oral technical presentations which included 17 invited talks, and 55 poster presentations.

Although this special issue is intended to reflect the breadth of the conference and the caliber of papers presented, in order to ensure that only articles of high quality are published in JTST, only ten papers out of the more than 120 presentations were accepted and included in this issue. The time devoted by several experts, including Masahiro Fukumoto, Robert Vassen, Hanlin Liao, Hua Li, Changhee Lee, and Kazuhiro Ogawa, who assisted us with the preliminary evaluation of the submitted abstracts was greatly appreciated. We must also mention our sincere gratitude to the reviewers who provided invaluable input to us and the authors.

\section{Guest Editors}

Seiji Kuroda

National Institute for Materials Science, Japan

Chang-Jiu Li

Xi'an Jiaotong University, China 